\title{
Patterns in complex hydraulic fractures observed by true-triaxial experiments and implications for proppant placement and stimulated reservoir volumes
}

\author{
Luke P. Frash ${ }^{1,2}$. Jesse Hampton ${ }^{2,3} \cdot$ Marte Gutierrez $^{2} \cdot$ Azra Tutuncu $^{2} \cdot$ J. William Carey ${ }^{1}$ John Hood ${ }^{2}$. \\ Mehdi Mokhtari $^{2,4} \cdot$ Hai Huang ${ }^{5} \cdot$ Earl Mattson $^{5}$
}

Received: 1 November 2018 / Accepted: 6 May 2019 / Published online: 23 May 2019

(c) The Author(s) 2019

\begin{abstract}
Rocks are host to complex fracture networks that are difficult to locate in situ, and yet characterization of these fractures is crucial to predicting the effects of hydraulic stimulation. We analyze three-dimensional hydraulic fracture patterns among varied laboratory experiments to identify recurring geometries. Building on the constitutive tensile and shear fracture modes, we observe examples of offset fracture branching, traversing fracture coalescence, and smooth fracture reorientation as relatively simple structures within complex fracture networks. The evolution of fracture branching, also referred to as stranding, is revealed to be a fundamentally three-dimensional process, in which continued propagation can result in traversing fracture coalescence. Fracture branching, therefore, can create an illusion of unconnected, staggered, and offset hydraulic fracture growth when viewed from a single cross section; meanwhile, these fractures are likely connected through a common fracture surface elsewhere. The fractures are also investigated at a smaller scale, where similar fracture patterns are observed. In the field, these complex patterns are likely to hinder proppant settling, reduce open fracture permeability, create larger fracture surface areas, and lead to increased stimulated reservoir volumes. A balance of stimulation methods to prevent this complexity in some areas and exploit it in others could be key to improving recovery from oil and gas resources, improving geothermal energy efficiency, and optimizing disposal of waste water or $\mathrm{CO}_{2}$ via injection wells. Representation of these complex structures is needed for accurate modeling predictions for reservoir management.
\end{abstract}

Keywords Branching $\cdot$ Coalescence $\cdot$ Fracture network $\cdot$ Mixed mode $\cdot$ Tortuosity

\section{Introduction}

Productivity and injectivity in low-permeability rock formations are strongly dependent upon the well intersecting and hydraulically connecting with permeable fractures,

Electronic supplementary material The online version of this article (https://doi.org/10.1007/s13202-019-0681-2) contains supplementary material, which is available to authorized users.

Luke P. Frash

lukepfrash@gmail.com

Los Alamos National Laboratory, Los Alamos, NM, USA

2 Colorado School of Mines, Golden, CO, USA

3 New England Research, White River Junction, VT, USA

4 University of Louisiana at Lafayette, Lafayette, LA, USA

5 Idaho National Laboratory, Idaho Falls, ID, USA whether natural or anthropogenic. The apertures and lengths of these connected fractures can be considered the dominant factors controlling permeability (Witherspoon et al. 1980), but tortuosity, contact area, fracture network connectivity, and roughness are also very important (Hyman et al. 2016; Makedonska et al. 2016; Zimmerman and Bovarsson 1996). In this study, we loosely use the term 'fracture geometry' to imply any or all physical spatial characteristics (i.e., length, height, twist, aperture, spacing, roughness, etc.). Fracture geometries are often complex, as opposed to simple planar features, due to changing stress states and the influence of heterogeneity and discontinuities throughout the rock mass (Aydin et al. 2006; Einstein and Dershowitz 1990; Hoek and Martin 2014).

Multiple intersecting fractures form complex fracture networks. These may include a combination of natural fractures, tensile hydraulic fractures, sheared weak discontinuities, and pressure solution interfaces (McClure and Horne 
2014). Microseismic data acquired during hydraulic stimulation can be used to estimate the extent of these complex fracture networks, sometimes referred to as the stimulated reservoir volume (Mayerhofer et al. 2010). However, the actual geometry of these interconnected complex fracture networks is very difficult to characterize in situ (Warpinski et al. 1982a, b; Jeffrey et al. 1995). Fracture roughness, branching, and geometric complexity during hydraulic stimulation can cause increased frictional pressure losses and hinder proppant transport (Jeffrey et al. 2009), which in turn will affect fracture network permeability after fracture closure. Fracture tortuosity, roughness, and asperity contact area reduce fracture permeability (Detwiler and Morris 2014; Pyrak-Nolte and Morris 2000; Warpinski and Teufel 1987; Zimmerman and Bovarsson 1996). Branching and roughness increase fracture surface area. In natural rocks, it is impossible to confidently predict the geometry of stimulated fractures a priori because of uncertainty arising from heterogeneity and undetected or insufficiently characterized pre-existing fractures, even if only considering the targeted zone for stimulation. Therefore, it is important to understand the possible geometries of hydraulic stimulated fractures that are likely to occur in the field in order to better predict the effectiveness of a stimulation treatment. This is especially important in multi-stage hydraulic fracture treatments, where an optimal spacing of hydraulic fracture stimulation intervals along a horizontal well is thought to exist, such as for oil and gas or enhanced geothermal energy production.

In this study, we analyze three-dimensional hydraulic fracture geometry from a series of varied experiments in order to identify recurring patterns. The experiments included specimens of different materials with different sizes and different boundary conditions. Building from the well-known constitutive tensile and shear fractures, we identify the recurring higher-order patterns of offset fracture branching, traversing coalescence, and smooth fracture reorientation. These patterns occurred in homogeneous and heterogeneous materials and combine to form complex fracture networks. Identifying these common fracture structures elucidates geometrical features that are likely to influence fluid flow. We also evaluate the implications of these structures for proppant settling, fracture permeability, fracture surface area, and stimulated reservoir volume in the context of applications for oil and gas recovery, geothermal energy mining, waste disposal, and $\mathrm{CO}_{2}$ sequestration.

\section{Background: hydraulic fracture geometry}

Many hydraulic fracture experiments have been performed in rocks subjected to a variety of stress conditions. Some of these studies also present data regarding hydraulic fracture geometry. These studies generally found that hydraulic fracture geometry depends upon the rock stress-state, borehole and perforation geometry, fluid viscosity and injection rate, and rock structure and scale.

Previous studies have identified many important trends between experimental parameters and resulting fracture geometries. Rock stresses are the dominant factor affecting fracture geometry with tensile hydraulic fractures preferentially orienting perpendicular to the minimum principal stress direction (Warpinski et al. 1982a, b; Zoback et al. 1977). The influence of the near-wellbore zone can add complexity to the fracture, where examples show that fractures tend to initiate with orientations parallel with the borehole axis even if the borehole is drilled parallel with the minimum principal stress (Hallam and Last 1991; Romero et al. 1995). It is relevant to note that these studies observed an offset branching pattern along the wellbore when hydraulic fractures initiated at an angle other than perpendicular to the minimum principal stress (Weijers et al. 1994), which is unlike the idealized curving pattern predicted by continuum theory (Abass et al. 1996; Valkó and Economides 1995). Perforations can affect fracture growth where misalignment between the perforations and the maximum principal rock stress can add tortuosity (Behrmann and Elbel 1991; Daneshy 1973). When the initial hydraulic fracture at the well is not perpendicular to the minimum principal field stress, twisting fractures can form as the fracture lengthens and far-field stress effects become dominant (Valkó and Economides 1995). Fluid viscosity and injection rate have a strong influence on propagating fracture geometry and its interaction with natural discontinuities (Beugelsdijk et al. 2000) where higher viscosities and flow rates can produce more planar fractures (Ishida et al. 2004) and very high injection rates, as with conflagration and explosive compounds, can produce more fracture branching (Cuderman and Northrop 1986; Wieland et al. 2006). Fluid-rock chemical interactions can affect fracture aperture distribution over time (Detwiler 2010). Permeation of fracture fluid into the matrix and frictional pressure losses with fluid flow through open fractures can reduce fracture aperture and length (Perkins and Kern 1961; Nordgren 1972; Geertsma and de Klerk 1969; Warpinski 1985).

Dimensional scale affects fracture geometry and roughness. For example, a small pre-existing fracture at $1 \mathrm{~mm}$ length will have a lesser effect on an intersecting $1 \mathrm{~m}$ hydraulic fracture than a $10 \mathrm{~m}$ pre-existing fracture. Most theoretical work concerning hydraulic fracture scaling focuses on continuum materials (de Pater et al. 1994; Johnson and Cleary 1991; Detournay et al. 2007), but field conditions and the laboratory use of natural rocks unavoidably include heterogeneity and discontinuity (Athavale and Miskimins 2008; Jeffrey et al. 2009; Mokhtari et al. 2014; Warpinski and Teufel 1987). We do not attempt to directly address 
the topic of discontinuous-heterogeneous scaling in this study; however, we do investigate hydraulically stimulated fractures in different-sized specimens and specimens that contain discontinuities ranging in size with respect to the specimens. From these, we find prevalent fracture patterns at a range of scales from sub-specimen to full specimen.

Uncertainty remains regarding the mechanisms for complex hydraulic fracture growth in heterogeneous and discontinuous rocks. A better understanding of this process can provide an improved means for evaluating complex fracture networks, whether actual or modeled. This in turn can lead to improved design of stimulation treatments.

\section{Shear and tensile fracture identification}

Fracture propagation can be categorized according to linear elastic fracture mechanics (LEFM) into one of the three principal directions of crack tip motion, (mode I) tensile opening, (mode II) in-plane shearing, and (mode III) outof-plane shearing (Anderson 1991). These displacements can be determined after fracturing from characteristics such as texture, offset, and orientation with respect to the expected stress-field in which they were created (Aydin et al. 2006). Mixed mode fractures, including any combination of these three displacement modes, are common in rock because of natural heterogeneities and discontinuities.
LEFM mechanics has been applied to hydraulic fracture breakdown pressure prediction and fracture propagation modeling for adequately homogeneous rock types, known stress conditions, and sufficiently characterized rock properties (Valkó and Economides 1995). When applied to natural fracture networks, LEFM is complicated by uncertainty in rock properties, heterogeneities, and pre-existing discontinuities. In this laboratory study, we assume shear- or tensiledominated fractures by orientation with respect to known applied principal stresses. Tensile-dominated fractures are identified as those oriented perpendicular to the minimum principal stress. Shearing fractures occur at angles between the principal stresses.

\section{Hydraulic fracture experiments}

In this study, we identify recurring hydraulic fracture patterns among a series of laboratory experiments. Details for each of the individual experiments are detailed in the prior work (Frash 2012, 2014; Frash et al. 2013a, b, 2014a, b, 2015a, b, c; Haas et al. 2013; Hampton et al. 2013; Revil et al. 2015). Table 1 gives an overview of the hydraulic stimulation experiments evaluated for this study, detailing the various specimen materials, injection fluids, and boundary conditions. Specimen materials included concrete, cement, granite, acrylic, and carbonate-rich shale, representing a

Table 1 Summary of laboratory experiments in which hydraulic stimulation was performed by fluid injection into a borehole and after which fractures were mapped from a series of sequential cross sections

\begin{tabular}{|c|c|c|c|c|c|c|c|}
\hline ID & $\begin{array}{l}\text { Material and } \\
\text { dimensions }{ }^{*}(\mathrm{~mm})\end{array}$ & Temp. $\left({ }^{\circ} \mathrm{C}\right)$ & $\begin{array}{l}\text { Vertical } \\
\text { stress } \\
(\mathrm{MPa})\end{array}$ & $\begin{array}{l}\text { Maximum } \\
\text { horizontal stress } \\
(\mathrm{MPa})\end{array}$ & $\begin{array}{l}\text { Minimum } \\
\text { horizontal stress } \\
\text { (MPa) }\end{array}$ & $\begin{array}{l}\text { Initial break- } \\
\text { down pressure } \\
(\mathrm{MPa})\end{array}$ & $\begin{array}{l}\text { Injected fluid for stimu- } \\
\text { lation }\end{array}$ \\
\hline P01-00 & $\begin{array}{l}\text { Concrete } \\
300 \times 300 \times 300\end{array}$ & $23^{\circ} \mathrm{C}$ & 0 & 0 & 0 & 6.4 & Brine \\
\hline P02-00 & $\begin{array}{l}\text { Concrete } \\
300 \times 300 \times 300\end{array}$ & $23^{\circ} \mathrm{C}$ & 0 & 0 & 0 & 5.0 & Oil \\
\hline E01-00 & $\begin{array}{l}\text { Cement } \\
300 \times 300 \times 293\end{array}$ & $23^{\circ} \mathrm{C}$ & 0 & 6.1 & 3.1 & 15.2 & Brine \\
\hline E02-00 & $\begin{array}{l}\text { Cement } \\
300 \times 300 \times 300\end{array}$ & $35^{\circ} \mathrm{C}$ & 13.3 & 8.6 & 4.4 & 15.1 & Oil \\
\hline A01-03 & $\begin{array}{l}\text { Acrylic } \\
38 \varnothing \times 140\end{array}$ & $23^{\circ} \mathrm{C}$ & 0 & 0 & 0 & 9.6 & Oil \\
\hline A01-04 & Acrylic $76 \varnothing \times 127$ & $23^{\circ} \mathrm{C}$ & 0 & 0 & 0 & 11.7 & Oil \& proppant \\
\hline A01-05 & Acrylic $76 \varnothing \times 127$ & $23^{\circ} \mathrm{C}$ & 0 & 0 & 0 & 8.9 & Marine epoxy \\
\hline G01-00 & Granite $300 \times 240 \times 300$ & $23^{\circ} \mathrm{C}$ & 0 & 0 & 0 & 49.4 & Oil \\
\hline G01-90 & Granite $300 \times 300 \times 300$ & $50^{\circ} \mathrm{C}$ & 12.8 & 8.6 & 4.3 & 18.0 & Oil \\
\hline G01-91 & Granite $300 \times 300 \times 300$ & $23^{\circ} \mathrm{C}$ & 0 & 0 & 0 & 50.9 & E-120HP ероху \\
\hline G01-92 & Granite $300 \times 300 \times 300$ & $25^{\circ} \mathrm{C}$ & 13.0 & 8.0 & 8.0 & 27.9 & Water \& proppant \\
\hline G01-93 & Granite $300 \times 300 \times 300$ & $80^{\circ} \mathrm{C}$ & 13.0 & 8.0 & 4.0 & 30.1 & Oil \& proppant \\
\hline S01-00 & $\begin{array}{l}\text { Shale } \\
300 \times 300 \times 300\end{array}$ & $23^{\circ} \mathrm{C}$ & 13.0 & 10.0 & 5.0 & 39.4 & E-60NC epoxy \\
\hline
\end{tabular}

*Dimensions given as length $\times$ width $\times$ height or diameter $(\varnothing) \times$ height 
large range of material types. Hydraulic fracture breakdown pressures were typically high due to scale effects from using small boreholes at $10 \mathrm{~mm}$ and $6 \mathrm{~mm}$ for cased and uncased intervals, respectively (Haimson and Zhao 1991). Available mechanical properties for each of these materials are given in Table 2 with additional description in the Appendix. Injection fluids included water, oil, and epoxies, as detailed in Table 3. Additional details and data for these experiments are available by reasonable request to the corresponding author.

Multiple hydraulic injection stages were executed for experiments P01-00, E01-00, E02-00, G01-00, G01-90, G01-92, and G01-93. Each injection stage included the possibility of new fracture growth; therefore, acoustic emission monitoring and/or real-time visual observation was used to estimate the location and timing of any new fractures activated or created by fluid injection. Pre-fracture inspections and a sequential series of post-fracture saw-cut cross sections were acquired from each of these experiments to measure hydraulically stimulated $3 \mathrm{D}$ fracture geometries. We find this saw-cut method to be more informative than the common method in the previous studies, where a hammer and chisel were used to mechanically split specimens parallel to the hydraulic fracture plane. Epoxy injection yielded the best fracture growth control, and the most pristine examples of complex fracture network geometry because fractures were better preserved and the path of injected fluid penetration into fractures and matrix was easily traceable, even when branching occured. Other methods such as X-ray tomography are available and have been successfully used for fracture identification in rocks, but these methods have difficulty resolving small-scale fracture structures within large specimens (Frash et al. 2016). For example, X-ray tomography would not be able to resolve $0.1 \mathrm{~mm}$ aperture fractures within a $300 \mathrm{~mm} \times 300 \mathrm{~mm} \times 300 \mathrm{~mm}$ cubic specimen at the current state of the technology.

Here, we first present results showing complex fracturing in acrylic specimens. Results from fracturing this relatively
Table 3 Injection fluid properties as used in the hydraulic stimulation experiments

\begin{tabular}{llll}
\hline Fluid & $\begin{array}{l}\text { Tem- } \\
\text { perature } \\
\left({ }^{\circ} \mathrm{C}\right)\end{array}$ & Viscosity $(\mathrm{cP})$ & Density $(\mathrm{g} / \mathrm{mL})$ \\
\hline Tap water & 23 & $9.42 \times 10^{-1}$ & 0.998 \\
& 50 & $5.46 \times 10^{-1}$ & 0.988 \\
& 80 & $3.54 \times 10^{-1}$ & 0.971 \\
Valvoline $^{\circledR}$ 80W90 oil & 23 & $3.23 \times 10^{2}$ & 0.887 \\
& 50 & $7.15 \times 10^{1}$ & - \\
& 80 & $2.26 \times 10^{1}$ & - \\
Do-It-Best & & \\
epoxy & 25 & $\sim 4.00 \times 10^{4}$ & $\sim 1.1$ \\
Loctite $^{\circledR}$ E-120HP epoxy & 25 & $\sim 3.00 \times 10^{4}$ & 1.1 \\
Loctite $^{\circledR}$ E-60NC epoxy & 25 & $\sim 8.00 \times 10^{3}$ & 1.05 \\
\hline
\end{tabular}

homogeneous and transparent acrylic material provide useful insight into understanding the experiments in opaque rocks and cements. Next, we present examples of recurring 3D fracture patterns observed at the full specimen scale, focusing on the least ambiguous results. Then, we show smaller, sub-specimen scale, fracture patterns where 2D evidence for similar structures to the large scale is found.

\section{Complex fractures in acrylic}

The most self-evident examples of simple tensile and shear fractures were acquired from A01-05, as shown in Fig. 1. The included photomicrographs were taken from cut cross sections through the hydraulic-fractured acrylic specimen. Injected epoxy (off-white/orange color) infilled the fractures in this experiment, preserving the fracture aperture during cross sectioning and enhancing contrast between fractures and the acrylic matrix. Similar fracture geometries were observed by eye in all of the acrylic specimens, but the tight residual fractures in A01-03 and A01-04 could not be easily

Table 2 Properties of specimen materials used for the hydraulic stimulation experiments

\begin{tabular}{llllll}
\hline Property & Concrete & Cement & Granite & Acrylic & Carbonate-rich shale \\
\hline Elastic modulus $(\mathrm{GPa})$ & $9.9 \pm 0.5$ & $24.3 \pm 5.0$ & 56.9 & $3.3 \pm 0.1$ & - \\
Poisson's ratio & - & $0.22 \pm 0.03$ & 0.32 & $0.38 \pm 0.01$ & - \\
Density $\left(\mathrm{g} / \mathrm{cm}^{3}\right)$ & $1.95 \pm 0.01$ & $2.12 \pm 0.03$ & $2.63 \pm 0.03$ & $1.18 \pm 0.01$ & $2.42 \pm 0.2$ \\
Porosity $(\%)$ & $31.1 \pm 0.5$ & $18 \pm 2$ & $0.8 \pm 0.1$ & 0 & $6.3 \pm 0.8^{*}$ \\
Permeability $(\mu \mathrm{D})$ & 10 to 100 & 1 to 10 & $\leq 1.2$ & 0 & 0.7 to $7.0^{*}$ \\
Uniaxial compression strength $(\mathrm{MPa})$ & $53.2 \pm 3.7$ & $135 \pm 13$ & $152 \pm 19$ & - & - \\
Indirect tensile strength $(\mathrm{MPa})$ & $2.47 \pm 0.25$ & $4.78 \pm 0.94$ & $7.5 \pm 1.8$ & - & $7.1 \pm 3.2^{*}$ \\
Shear wave velocity $(\mathrm{km} / \mathrm{s})$ & - & $2.28 \pm 0.01$ & 2.62 & - & $2.6 \pm 0.2$ \\
Compression wave velocity $(\mathrm{km} / \mathrm{s})$ & - & $3.59 \pm 0.03$ & 4.45 & - & $4.7 \pm 0.7$ \\
\hline
\end{tabular}

*Data from Mokhtari et al. (2014) 

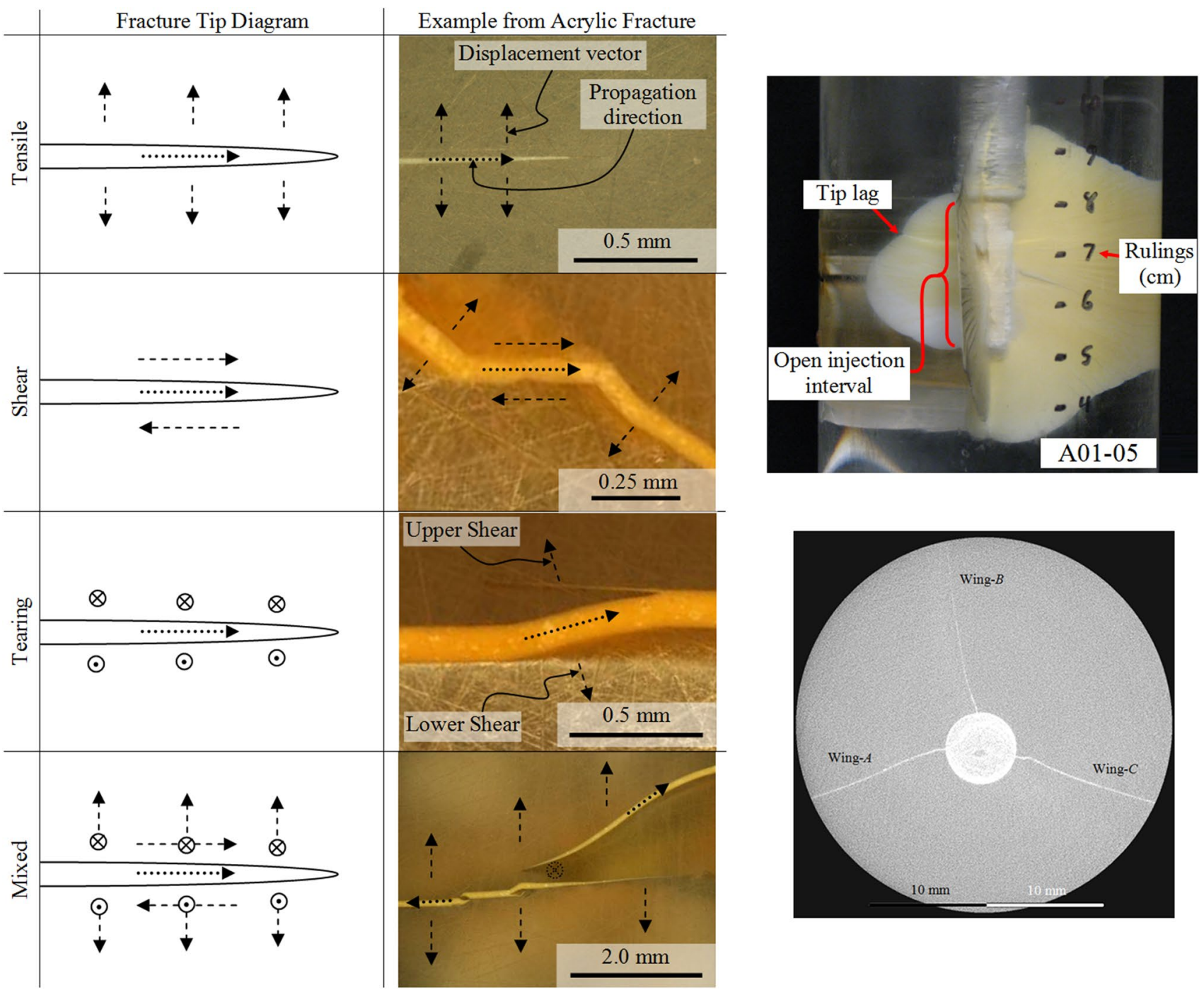

Fig. 1 Tensile (mode I), in-plane shear (shear; mode II), out-of-plane shear (tearing; mode III), and mixed-mode fractures observed in cross sections through the acrylic specimen A01-05. Marine epoxy (offwhite color) infilled the fractures preserving their geometry for cross sectioning. Tensile fractures were dominant with some offset tensile fractures connected by shear fractures, forming larger coalesced fractures. Top right shows a view of the fractured specimen. Bottom right shows an internal X-ray computed tomography slice near the center of the injection interval

tensile fractures begin to coalesce via new interconnecting fractures that likely include a mixture of shear modes. The tips of the shear-coalesced fracture fronts lag behind the tensile front with respect to radial distance from the borehole. This detail indicates that more strain is required to create the coalescing shear fractures than what is required to create the tensile fractures. The progression of fracture growth demonstrates that offset tensile fracture strands can simultaneously propagate on what could appear to be competing planes (e.g., stress shadowing) and later coalesce into a common fracture by shear (Fig. 1: mixed-mode example). The geometry in these experiments provides examples of: (1) hydraulic fractures propagating by different modes along segments within a larger coalesced ing. Then, at a critical amount of extension, these small 


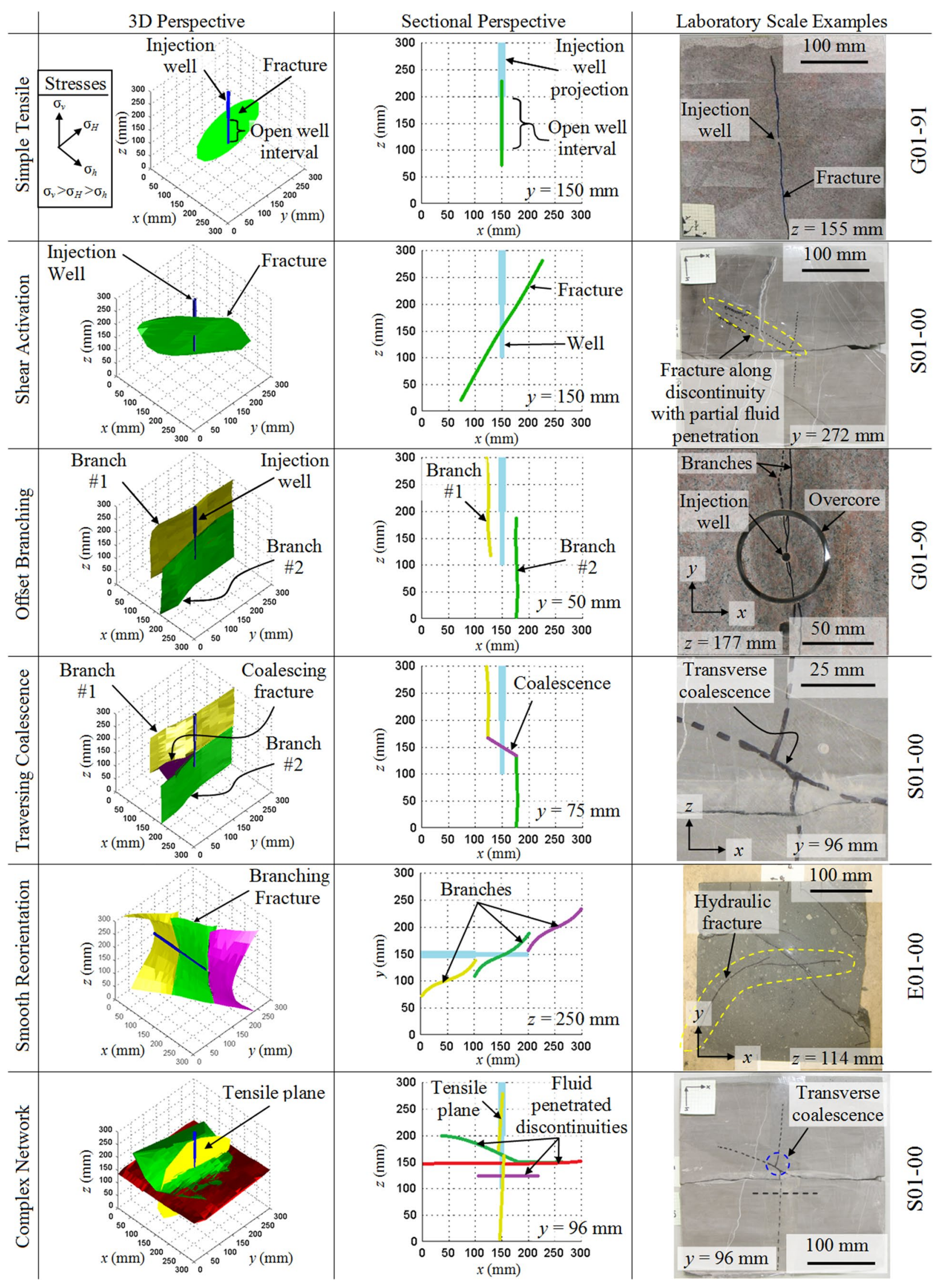


4Fig. 2 Categorization of fracture patterns created by hydraulic stimulation that combine to form complex fracture networks. Multiple perspectives are shown for each fracture pattern to depict their 3D structures, illustrate their 2D signatures, and provide evidence of their occurrence in the cement, granite, or shale experiments

fracture and (2) multiple fracture strands sharing a common plane closer to a common origin, even when they appear disconnected or separate from a 2D perspective.

\section{Recurring fracture patterns at the specimen scale}

It may not be immediately apparent how varied laboratory hydraulic fracture experiments can provide insight into complex fracturing processes in the subsurface. It is also common knowledge that natural rocks contain significant complexity (e.g., heterogeneity, discontinuity, anisotropy, nonlinearity, and variable stresses) that cannot be fully characterized across the relevant scales even using the most advanced available methods. In consequence and by subjective argument, it is useful to be able to identify recurring fracture geometries that occur across a range of material types subjected to differing boundary conditions. In this study, we categorize three characteristic 3D hydraulic fracture patterns of a higher order than simple tensile and shear modes. These higher-order patterns are proposed as constituents of even more complex fracture networks. Each higher-order fracture pattern hints at the origins of tortuosity, roughness, and branching and, in turn, has implications for hindered fluid flow and increased fracture surface area relative to more idealized fracture geometries. The three categorized fracture patterns include (1) offset branching, (2) traversing coalescence, and (3) smooth reorientation, as depicted in Fig. 2. Note that the '3D perspectives' column in Fig. 2 shares a common boundary stress orientation with the $x$-axis being the minimum principal stress axis. The geometry shown for the complex network was produced from direct measurement (Frash et al. 2015a, b, c), while the other geometries are simplified from actual observations which tended to each include multiple fracture structures.

Simple tensile fractures are the simplest hydraulic fracture geometry and are a convenient assumed shape for modeling (de Pater et al. 1994; Perkins and Kern 1961; Nordgren 1972; Geertsma and de Klerk 1969). This geometry results from tensile-dominated fracture propagation radially away from the borehole and often exhibits an elliptical aperture profile (de Pater et al. 1994; Frash et al. 2014a, b). This was also the most commonly observed macro-scale fracture geometry with examples identified in all specimens except for E01-00 - true-triaxially confined high-strength cement with brine injection and G01-92 — triaxially confined granite with water injection. These laboratory results support the expectation that rock stresses, borehole orientation, and fluid parameters dominate over the influence of rock structure, particularly when high-viscosity fluids were used (de Pater et al. 1994; Ishida et al. 2004; Warpinski et al. 1982a, b).

Discontinuity shear was observed at some scale in all experiments with the most prominent examples identified in E01-00-true-triaxially confined high-strength cement with brine injection, E02-00-true-triaxially confined high-strength cement with oil injection, and S01-00 - truetriaxially confined shale with epoxy injection. In each of these, large and prolific pre-existing discontinuities were hydrosheared by fluid injection because these fractures were weaker than the intact matrix rock (Mokhtari et al. 2014). The result from S01-00 was particularly interesting because a large shearing event occurred suddenly during low-rate constant-pressure injection at what was thought to be an injection pressure below the hydraulic fracture propagation pressure (Frash et al. 2015a, b, c). This indicates a transient effect where slow pressurization of a natural fracture eventually resulted in shear slip.

Offset fracture branching was observed in all specimens. At the field scale, similar hydraulic fracture branching has been described as a hydraulic fractured zone (Warpinski and Teufel 1987) or as a fracture band (Aydin et al. 2006). This structure often appears in cross sections as a set of unconnected or weakly connected sub-parallel hydraulic fractures. However, in many cases, these branches could be traced back to a common fracture plane closer to the injection well. Considering observations from the acrylic specimens, it is evident that these branches can propagate simultaneously, in parallel, overlapping, and in close proximity without significant competition from stress shadowing. The offset branching structure is significant for fluid flow. Lateral offsets in vertical fractures are likely to hinder proppant settling. Overlapping parallel branched fractures are likely to each have reduced aperture relative to a single fracture plane which will reduce both individual and cumulative hydraulic conductivities. Increased surface area from branched fractures will likely improve flow from matrix pores to the more conductive hydraulic fractures per length of the fracture, as well as enhance reactivity because new fracture surfaces tend to be highly reactive. The number of fracture branches does not appear to be predictable, but it is possible that they have some relation to distance from the well.

Traversing coalescence of branched fractures is a structure that sometimes occurred as branched fractures extended. It appears that this structure was the most common when branched fractures propagated in close proximity or that this structure caused branched fractures to propagate close together. Prominent examples of traversing coalescence were identified in A01-05-unconfined acrylic with epoxy injection and S01-00_-true-triaxially confined shale with epoxy injection. The effects of traversing coalescence are

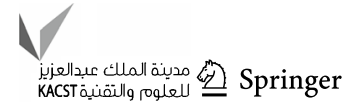


likely to be the opposite of branching with a tendency to decrease fracture surface area, increase fracture aperture, and decrease tortuosity, especially as fracture size increases. The sequence of traversing coalescence occurring after branching is indicative of discontinuous processes in fracture propagation. This discontinuous nature of propagation is further supported by a known tendency for irregular pressure peaks during continuous injection stimulation (Frash et al. 2015a, b, c).

Smooth reorientation was most commonly observed as fractures transitioned from longitudinal with the wellbore in the near-well zone to be perpendicular to the minimum principal stress further from the well. This curvilinear geometry was less apparent in our experiments than in previous works that used larger wellbores and more homogeneous materials (Abass et al. 1996; Hallam and Last 1991; Romero et al. 1995; Weijers et al. 1994). Our most prominent examples of smooth reorientation were observed in E01-00-true-triaxially confined high-strength cement with brine injection and G01-90- true-triaxially confined granite with oil injection. Fracture branching was common amidst smooth reorientation. These branches generally arose from multiple tensile fracture initiation points along the well or by interaction with pre-existing fractures during propagation. Tortuosity due to smooth reorientation is likely to affect flow by increasing frictional pressure losses, especially near the wellbore.

Combinations of these recurring fracture structures yield complex fracture networks. A prominent example of a complex fracture network was observed in S01-00-true-triaxially confined shale with epoxy injection. This experiment produced a simple tensile planar bi-wing fracture, shear activation of a pre-existing discontinuity, and fluid penetration into bedding planes. Among these primary structures was evidence for offset fracture branching followed by traversing coalescence. No significant smooth reorientation of fractures was observed, likely because the injection well was drilled parallel to the maximum principal stress. Most fracture branching occurred at the small scale, but some branching also occurred at the macro-scale with influence from shear activated discontinuities. When offset fracture branches were traced back to the injection borehole, they were found to share a common plane. It is clear that the complex hydraulic fractures stimulated in this experiment penetrate a larger fracture volume and greater surface area than a simple tensile fracture alone would have.

\section{Small-scale fracture patterns}

Microscopic inspection of the cut cross sections from the laboratory hydraulic fracture experiments revealed fracture complexity similar to the macroscopic scale, as shown in Fig. 3. At the macroscopic perspective, this complexity is often lumped into the description of roughness and generated fines (i.e., loose particles). Experiments using epoxy injection provided the best detail on microscopic fracture structures and produced the examples shown in Fig. 3. From observation, simple tensile fractures included propagation by void nucleation and coalescence and by transgranular fracturing. Shear activation was typically observed with intergranular fracturing; however, microscale intergranular fracturing was also observed within macroscale simple tensile fractures. A special case of microscale fracturing included granular fracture bifurcation which is a branching process likely related to offset branching. Another special case included transportable grain release where fracture propagation was found to mobilize fine-sized particles. Without a detailed analysis or support from granular fracture models, evaluations of the mechanisms by which these structures arise would be merely hypothetical. The implications of these mechanisms are more self-evident, where void nucleation, fracture coalescence, and intergranular fracturing all contribute to fracture roughness which in turn causes increased frictional pressure losses in flowing fluids. Transportable grain release is an interesting special case, in that transportable fines could act as natural proppant or flowblocking particles. Granular fracture bifurcation is another interesting special case, in that it creates increased surface area within macroscopic fractures and also potentially contributes to macroscopic branching.

\section{Conclusions}

Building on fundamental simple tensile hydraulic fractures and shear activation of pre-existing discontinuities, we proposed the three higher-order fracture geometries of offset branching, traversing coalescence, and smooth reorientation, as depicted in Fig. 2. Combinations of these geometries yield complex fracture networks that are observable across dimensional scales. We observed them via laboratory experiments conducted using a variety of materials subjected to a variety of conditions. Observations of fracture geometries were best via cut cross sections and injection of clearly traceable fluids such as epoxy. In both homogeneous and heterogeneous materials, offset fracture branching was often found to share a common fracture closer to the point of injection. This common fracture was coalesced from smaller close-proximity tensile-dominated branches via traversing shear-oriented fractures that lagged behind the tensile fracture front. Smooth fracture reorientation was prevalent when the injection borehole was not aligned with a principal stress direction. In this case, hydraulic fractures that initiated semi-longitudinally along the wellbore would twist and reorient to be perpendicular to the minimum principal stress further from the point of injection. Instances of 


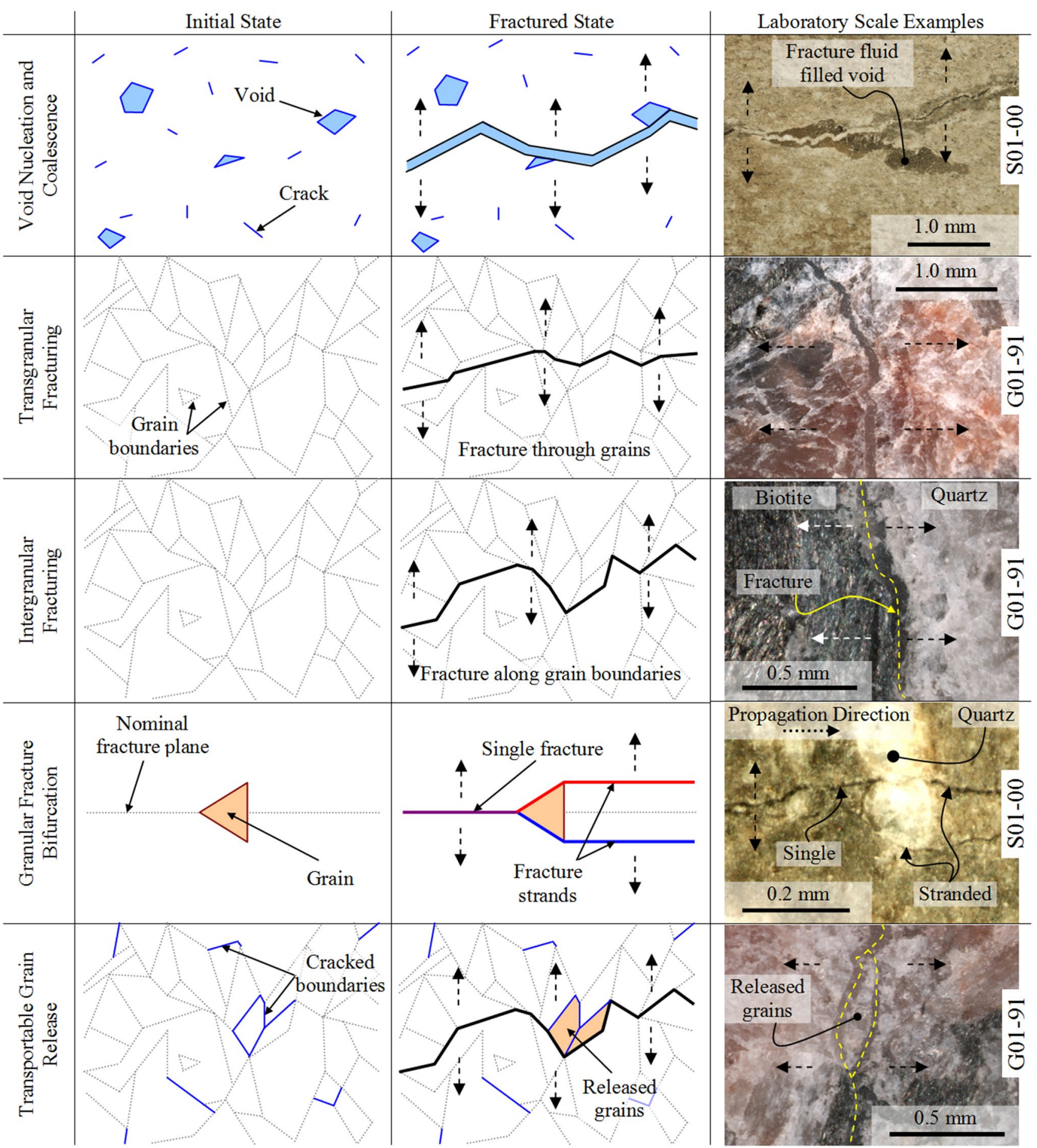

Fig. 3 Microscopic fracture patterns with examples from the experiments

offset branching and traversing coalescence were observed amidst the reorienting fracture. The three proposed higherorder fracture geometries are not new fracturing modes but rather recurring manifestations of mixed fracture modes.

Evidence that higher-order complex fracture geometries occur and identification of common structures for these geometries provide useful insight related to hydraulic fracture stimulations. For example, well stimulation methods that encourage fracture branching could provide increased fracture surface area and increased stimulated reservoir volumes for a given amount of injected fluid volume. This would be beneficial for increasing oil and gas recovery 
because it will connect the stimulated well to more of the rock matrix. Also in this process, offset fracture branches would beneficially limit proppant settling to within semiisolated vertical segments of fractures. Possible methods for encouraging branching include low-viscosity or lowrate injection with slickwater or gas fracs. For an opposite example, stimulation methods that encourage simple tensile fracturing or traversing coalescence could result with more conductive and open fractures that counteract tortuosity. Possible methods for this include high-rate or high-viscosity fluid injection using gels or more horsepower. In practice, complex fractures should be expected in hydraulic fracture stimulation and accurate modeling of these structures with consideration of the common patterns could contribute to more efficient development of natural gas and geothermal energy resources or disposal sites for waste or $\mathrm{CO}_{2}$.

Acknowledgements The support provided by Idaho National Laboratory (INL), Unconventional Natural Gas and Oil Institute (UNGI), and US Department of Energy (DOE) under DOE Grant No. DE-FE0002760 is gratefully acknowledged. Additional support was provided by Department of Energy (DOE) Basic Energy Sciences (DE-AC52-06NA25396) and the Los Alamos National Laboratory Director's Postdoctoral Award. The opinions expressed in this paper are those of the authors and not INL, LANL, UNGI, or DOE.

Open Access This article is distributed under the terms of the Creative Commons Attribution 4.0 International License (http://creativeco mmons.org/licenses/by/4.0/), which permits unrestricted use, distribution, and reproduction in any medium, provided you give appropriate credit to the original author(s) and the source, provide a link to the Creative Commons license, and indicate if changes were made.

\section{Appendix}

Typical and preferred test specimens were $300 \times 300 \times 300 \mathrm{~mm}^{3}$ cubes, but smaller specimens were also used when available. Test materials included PMMA acrylic, concrete, granite, and carbonate-rich shale with respective material properties given in Table 1. Material properties were measured using element tests following the procedures detailed by Frash (2012) and Mokhtari et al. (2014) which are closely based on relevant ASTM standards (D3967 2008; D7012 2010).

PMMA acrylic, poly(methyl methacrylate), was selected as a test material for its homogeneity, transparency and brittle fracture behavior. This material was used to validate laboratory hydraulic methods, where fracture growth could be visually observed. Acrylic specimens included commercially available cylinders of 38 or $76 \mathrm{~mm}$ diameter.

Concretes used included commercially available grout mix and a custom mix designed for high strength and low porosity. The custom concrete was a low water mix strengthened with high-range water reducer, air remover, and microsilica (silica fume). Both concretes included only fine aggregates with the commercial mix containing up to $0.42 \mathrm{~mm}$ diameter (40 mesh) sand grains and the custom concrete containing up to $0.30 \mathrm{~mm}$ diameter (50 mesh) sand grains. Fine grains were used to reduce the ratio of grain diameter to specimen size for scaling purposes. Specimens produced from these concretes exhibited high homogeneity and higher permeability than the natural rock materials. A $300 \times 300 \mathrm{~mm}^{2}$ rigid steel form was used to cast specimens where excess material from the top was trimmed by diamond sawing to give $300 \mathrm{~mm}$ specimen height.

Granite was obtained from the Liesveld Quarry in Lyons, Colorado, USA. This material was extracted from an outcrop using water jet cutting and trimmed to size with a diamond wire saw. Major minerals included quartz, feldspars, muscovite, and biotite. Typical crystal grain sizes ranged up to $30 \mathrm{~mm}$ in length where larger grains were composites structures containing sub-grains, striations, and inclusions. Sub-grains were estimated to have a size range of 0.001 to $0.1 \mathrm{~mm}$ from the inspection of photomicrographs having $0.0005 \mathrm{~mm} /$ pixel maximum resolution.

Carbonate-rich shale was obtained from the Cemex quarry in Lyons, Colorado, USA. This material was extracted from the Fort Hays carbonate-rich shale member of the Niobrara shale formation using open-pit mining. Effort was taken to select intact specimens with minimal damage. The mineral composition for this material is approximately $86 \%$ calcite, $5 \%$ quartz, and 5\% illite with $2.6 \%$ total organic content by weight (Mokhtari et al. 2014). The structure of this carbonate-rich shale included horizontal bioturbated bedding planes and three dominant joint sets with calcite infilling. Two of the joint sets were sub-vertically oriented and crossing at $65^{\circ}$. One of the vertical joint sets was oriented within $10^{\circ}$ of the maximum horizontal principal stress during laboratory experiments with true-triaxial conditions applied. The third joint set was dipping at $25^{\circ}$ with a strike sub-parallel with the applied maximum horizontal stress. Bedding planes were oriented horizontally in the true-triaxial apparatus. Joint spacing was varied with a typical range of 10 to $40 \mathrm{~mm}$. Average grain size was less than $0.0005 \mathrm{~mm}$ for this calcareous rock; however, included quartz grains were measured at up to $0.30 \mathrm{~mm}$.

Injection fluids included water, brine, oil, and epoxy with the respective properties given in Table 2 (White 2009; ASTM D341 2009). These fluids represent a wide viscosity range of 0.35 to $40,000 \mathrm{cP}$. Hydraulic fracturing with epoxy provided the best fracture geometry data which included clear results regarding fluid penetration, fracture branching, and open fracture widths (aperture). Ballotini ${ }^{\circledR}$ glass beads ranging from 0.045 to $0.090 \mathrm{~mm}$ diameter (170 to 325 mesh) were added to the injection fluid for proppant in some experiments. The viscosity of the Do-It-Best ${ }^{\circledR}$ epoxy 
given in Table 2 is an estimate with an expected accuracy of $\pm 25 \%$.

\section{References}

Abass HH, Hedayati S, Meadows DL (1996) Nonplanar fracture propagation from a horizontal wellbore: experimental study. SPE Prod Fac 11(3):133-137

Anderson TL (1991) Fracture mechanics: fundamentals and applications. CRC Press, Boston

ASTM Standard D3967-08 (2008) Standard test method for splitting tensile strength of intact rock core specimens. In: Annual book of ASTM standards. ASTM International, West Conshohocken

ASTM Standard D341-09 (2009) Standard Practice for Viscosity-Temperature Charts for Liquid Petroleum Products. In: Annual Book of ASTM Standards. West Conshohocken: ASTM International

ASTM Standard D7012-10 (2010) Standard test method for compressive strength and elastic moduli of intact rock core specimens under varying states of stress and temperatures. In: Annual book of ASTM standards. ASTM International, West Conshohocken

Athavale AS, Miskimins JL (2008) Laboratory hydraulic fracturing tests on small homogeneous and laminated blocks. In: Proceedings of the 42nd US rock mechanics symposium, San Francisco, CA, 29 June-2 July

Aydin A, Borja RI, Eichhubl P (2006) Geological and mathematical framework for failure modes in granular rock. J Struct Geol 28:83-98

Behrmann LA, Elbel JL (1991) Effect of perforations on fracture initiation. J Pet Technol 43(5):608-615

Beugelsdijk LJL, de Pater CJ, Sato K (2000) Experimental hydraulic fracture propagation in a multi-fractured medium. SPE Asia Pacific conference on integrated modelling for asset management, Yokohama, Japan, 25-26 April

Cuderman JF, Northrop DA (1986) A propellant-based technology for multiple-fracturing wellbores to enhance gas recovery: application and results in Devonian Shale. SPE Prod Eng 1(2):97-103

Daneshy AA (1973) Experimental investigation of hydraulic fracturing through perforations. J Pet Technol 25(10):1201-1206

de Pater CJ, Cleary MP, Quinn TS, Barr DT, Johnson DE, Weijers L (1994) Experimental verification of dimensional analysis for hydraulic fracturing. SPE Prod Fac 9(4):230-238

Detournay E, Peirce AP, Bunger AP (2007) Viscosity-dominated hydraulic fractures. In: Proceedings of the 1st Canada-U.S. rock mechanics symposium, Vancouver, Canada, 27-31 May

Detwiler RL (2010) Permeability alteration due to mineral dissolution in partially saturated fractures. J Geophys Res 115

Detwiler RL, Morris JP (2014) Transmissivity anisotropy in roughwalled fractures: the combined influence of shear offset and normal deformation. In: Proceedings of the 48th US Rock Mechanics/ Geomechanics Symposium, Minneapolis, MN, 1-4 June

Einstein HH, Dershowitz WS (1990) Tensile and shear fracturing in predominantly compressive stress fields-a review. Eng Geol 29:149-172

Frash L (2012) Laboratory simulation of an enhanced geothermal reservoir. MS thesis, Colorado School of Mines, Golden, CO; October

Frash LP (2014) Laboratory scale study of hydraulic fracturing in heterogeneous media for enhanced geothermal systems and general well stimulation, $\mathrm{PhD}$ thesis, Colorado School of Mines, Golden, $\mathrm{CO}$

Frash L, Gutierrez M, Hampton J (2013a) A laboratory investigation of reversible permeability decline effects during flow through stimulated fracture networks: implications for improved EGS reservoir operation methodologies. In: Proceedings of the thirtyeighth workshop on geothermal reservoir engineering, Stanford, CA, 11-13 February

Frash L, Gutierrez M, Hampton J (2013b) Scale model simulation of hydraulic fracturing for EGS reservoir creation using a heated true-triaxial apparatus. In: Bunger A, McLennan J, Jeffery R (eds) Effective and sustainable hydraulic fracturing. InTech, Rijeka

Frash L, Hood J, Gutierrez M (2013c) Hydraulic fracture visualization: fracking acrylic with epoxy. http://youtu.be/PEXOE2FTD1 I. Accessed 28 Jul 2014

Frash LP, Gutierrez M, Hampton J (2014a) True-triaxial apparatus for simulation of hydraulically fractured multi-borehole hot dry rock reservoirs. Int J Rock Mech Min Sci 70:496-506

Frash LP, Hood J, Gutierrez M, Huang H, Mattson E (2014b) Laboratory measurement of critical state hydraulic fracture geometry. In: Proceedings of the 48th US rock mechanics/geomechanics symposium, Minneapolis, MN, 1-4 June

Frash LP, Gutierrez M, Hampton J (2015a) Laboratory-scale-model testing of well stimulation by use of mechanical-impulse hydraulic fracturing. SPE J 20(3)

Frash LP, Gutierrez M, Hampton J, Hood J (2015b) Laboratory simulation of a binary and triple well EGS in large granite blocks using AE events for drilling guidance. Geothermics 55:1-15

Frash LP, Gutierrez M, Tutuncu A, Hood J, Mokhtari M (2015c) Truetriaxial hydraulic fracturing of Niobrara carbonate rock as an analogue for complex oil and gas reservoir stimulation. In: Proceedings of the 49th U.S. rock mechanics/geomechanics symposium, San Francisco, 28 June-1 July

Frash LP, Carey JW, Lei Z, Rougier E, Ickes T, Viswanathan H (2016) High-stress triaxial direct-shear fracturing of Utica shale and in situ X-ray microtomography with permeability measurement. J Geophys Res Solid Earth 121:5493-5508

Geertsma J, de Klerk F (1969) A rapid method of predicting width and extent of hydraulically induced fractures. JPT 21(12):1571-1581

Haas AK, Revil A, Karaoulis M, Frash L, Hampton J, Gutierrez M, Mooney M (2013) Electrical potential source localization reveals a borehole leak during hydraulic fracturing. Geophysics 78(2):D93-D113

Haimson B, Zhao Z (1991) Effect of borehole size and pressurization rate on hydraulic fracture breakdown pressure. In proceedings of the 32nd U.S. symposium on rock mechanics (USRMS), 10-12 July, Norman, OK

Hallam SD, Last NC (1991) Geometry of hydraulic fractures from modestly deviated wellbores. JPT 43(6):742-748

Hampton J, Frash L, Gutierrez M (2013) Investigation of laboratory hydraulic fracture source mechanisms using acoustic emission. In: 47th U.S. rock mechanics/geomechanics symposium, San Francisco, California, 22-26 June

Hoek E, Martin CD (2014) Fracture initiation and propagation in intact rock-a review. J Rock Mech Geotech Eng 6:287-300

Hyman JD, Aldrich G, Viswanathan H, Makedonska N, Karra S (2016) Fracture size and transmissivity correlations: implications for transport simulations in sparse three-dimensional discrete fracture networks following a truncated power law distribution of fracture size. Water Resour Res 52:6472-6489

Ishida T, Chen Q, Mizuta Y, Roegiers J (2004) Influence of fluid viscosity on the hydraulic fracturing mechanism. J Energy Resour Technol ASME 126:190-200

Jeffrey RG, Settari A, Smith NP (1995) A comparison of hydraulic fracture field experiments, including mineback geometry data, with numerical fracture model simulations. In: Proceedings of the SPE annual technical conference and exhibition, Dallas, TX, 22-25 October

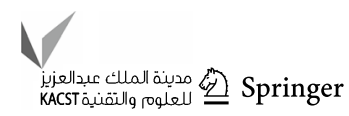


Jeffrey RG, Zhang X, Thiercelin MJ (2009) Hydraulic fracture offsetting in naturally fractures reservoirs: quantifying a long-recognized process. SPE hydraulic fracturing technology conference, The Woodlands, Texas, 19-21 January

Johnson E, Cleary MP (1991) Implications of recent laboratory experimental results for hydraulic fractures. In: Proceedings of the low permeability reservoirs symposium, Denver, Colorado, 15-17 April

Makedonska N, Hyman JD, Karra S, Painter SL, Gable CW, Viswanathan HS (2016) Evaluating the effect of internal aperture variability on transport in kilometer scale discrete fracture networks. Adv Water Resour 94:486-497

Mayerhofer MJ, Lolon EP, Warpinski NR, Cipolla CL, Walser D, Rightmire CM (2010) What is stimulated reservoir volume? SPE Prod Oper 25(1):89-98

McClure MW, Horne RN (2014) Characterizing hydraulic fracturing with a tendency-for-shear-stimulation test. SPE Reserv Eval Eng 17(2):233-243

Mokhtari M, Tutuncu AN, Kazemi H (2014) Integrated study on tensile fracture mechanics and subsequent flow in naturally-fractured Niobrara shale. In: Proceedings of the 48th US rock mechanics/ geomechanics symposium, Minneapolis, MN, 1-4 June

Nordgren RP (1972) Propagation of a vertical hydraulic fracture. SPE J. 12(4):306-314

Perkins TW, Kern LR (1961) Widths of hydraulic fractures. JPT 13(9):937-949

Pyrak-Nolte LJ, Morris JP (2000) Single fractures under normal stress: the relation between fracture specific stiffness and fluid flow. Int J Rock Mech Min Sci 37:245-262

Revil A, Mao D, Haas AK, Karaoulis M, Frash L (2015) Passive electrical monitoring and localization of fluid leakages from wells. $\mathrm{J}$ Hydrol 521:286-301

Romero J, Mack MG, Elbel JL (1995) Theoretical model and numerical investigation of near-wellbore effects in hydraulic fracturing. In: Proceedings of the SPE annual technical conference \& exhibition, Dallas, TX, 22-25 October
Valkó P, Economides M (1995) Hydraulic fracture mechanics. Wiley, New York

Warpinski NR (1985) Measurement of width and pressure in a propagating hydraulic fracture. SPE J 25(1):46-54

Warpinski NR, Teufel LW (1987) Influence of geologic discontinuities on hydraulic fracture propagation. J Pet Technol 39(2):209-220

Warpinski NR, Clark JA, Schmidt RA, Huddle CW (1982a) Laboratory investigation on the effect of in situ stresses on hydraulic fracture containment. SPE J 22(3):333-340

Warpinski NR, Schmidt RA, Northrop DA (1982b) In-situ stresses: the predominant influence on hydraulic fracture containment. JPT 34(3):653-664

Weijers L, de Pater CJ, Owens KA, Kogsbøll HH (1994) Geometry of hydraulic fractures induced from horizontal wellbores. SPE Prod Fac 9(2):87-92

White FM (2009) Fluid mechanics, 6th edn. McGraw-Hill, Boston

Wieland CW, Miskimins JL, Black AD, Green SJ (2006) Results of a laboratory propellant fracturing test in a Colton Sandstone block. In: Proceedings of the SPE ATCE, San Antonio, 25-27 September

Witherspoon PA, Wang JSY, Iwai K, Gale JE (1980) Validity of cubic law for fluid flow in a deformable rock fracture. Water Resour Res 16:1016-1024

Zimmerman RW, Bovarsson GS (1996) Hydraulic conductivity of rock fractures. Trans. Porous Media. 23:1-30

Zoback MD, Rummel F, Jung R, Raleigh CB (1977) Laboratory hydraulic fracturing experiments in intact and pre-fractured rock. Int J Rock Mech Min Sci 14:49-58

Publisher's Note Springer Nature remains neutral with regard to jurisdictional claims in published maps and institutional affiliations. 